\title{
Tensed Truthmaker Theory
}

\begin{abstract}
Presentism faces a serious challenge from truthmaker theory. Standard solutions to the truthmaker objection against presentism proceed in one of two ways. Easy road presentists invoke new entities to satisfy the requirements of truthmaker theory. Hard road presentists, by contrast, flatly refuse to give in to truthmaker demands. Recently, a third way has been proposed. This response seeks to address the truthmaking problem by tensing our truthmaker principles. These views, though intuitive, are under-developed. In this paper, I get serious about a fundamentally tensed approach to truthmaking by sketching out the underlying ontological picture needed to make sense of tensed truthmaker theory.
\end{abstract}

\section{Introduction}

According to presentism, only present entities exist; past and future entities do not. According to truthmaker theory, truth depends upon ontology; truth is not a primitive feature of reality. It has been argued that presentism is at odds with truthmaking. The problem lies with claims about the past. Such claims are true and yet, because past entities do not exist, their truth cannot be connected to ontology by the usual means, in the normal way.

Asay and Baron (2014) maintain that just two roads lay before the presentist: the easy road and the hard road. The easy road presentist capitulates to the demands of truthmaker theory. ${ }^{1}$ Accordingly, she typically inflates the ontology of the present with new kinds of entities (e.g. properties, abstract objects, relations, memories in God's mind and so on) drafting them into doing truthmaking work. ${ }^{2}$ The road is easy because it does not force one to take issue with truthmaker theory itself. The easy road can be summarised as follows:

\section{Easy Road Presentism}

\footnotetext{
${ }^{1}$ Fellow travellers include Bigelow (1996), Bourne (2006), Cameron (2011), Crisp (2007) and McKinnon and Bigelow (2012).

${ }^{2} \mathrm{By}$ 'ontology of the present' I mean: anything that exists now, along with any abstract objects one might be willing to countenance.
} 
1. Claims about the past are true.

2. The truth of claims about the past depends on presently existing entities.

3. Truthmaker theory is not restricted for claims about the past.

The hard road presentist refuses to capitulate. For her, truth is, sometimes, a primitive feature of reality; not all truths must be truthmade. The challenge of the hard road is to motivate and defend a restriction on truthmaker theory of the appropriate kind. ${ }^{3}$ The road is hard because it forces one to take up arms against standard maximalist truthmaker theory, which has benefited from a pretty formidable defense in recent times (see, for instance, Cameron (2008) and Armstrong (2004)). Hard road presentism can be summarised thus:

\section{Hard Road Presentism}

1. Claims about the past are true.

2. The truth of claims about the past does not depend on presently existing entities.

3. Truthmaker theory is restricted for claims about the past.

The distinction between the hard and easy roads, though useful, is not exhaustive. ${ }^{4}$ For there is a third road: the middle road to presentism. The middle road presentist maintains that we can fully accommodate the truth of claims about the past without calling up new existing entities to do truthmaking work, and without restricting truthmaker theory either. Middle road presentism can therefore be summarised as the combination of claim (2) from hard road presentism with claim (3) from easy road presentism: ${ }^{5}$

\section{Middle Road Presentism}

1. Claims about the past are true.

2. The truth of claims about the past does not depend on presently existing entities.

\footnotetext{
${ }^{3}$ Asay and Baron (2014) attribute the hard road to Tallant (2009). Sanson and Caplan (2010) and Merricks (2007) also seem to hold this view. Critics include Krämer (2010), Sider (2003, p. 185) and Heathwood (2007).

${ }^{4}$ In a recent paper, Baron (forthcoming) inverts the terminology: the hard road is the easy road and vice versa. I deploy Asay and Baron's (2014) terminology here, as I believe it more accurately captures the broad dialectical situation: defending a restriction on truthmaker theory is a much more challenging task than that of providing truthmakers for claims about the past.

${ }^{5}$ Kierland and Monton (2007), Baia (2012), Goff (2010) and Smith (1999) all suggest such a picture.
} 
3. Truthmaker theory is not restricted for claims about the past.

Middle road presentism is a 'have your cake and eat it too' kind of view. It is, therefore, apt to collapse into the easy or hard roads in a stiff breeze. Current middle road presentists defend the view by arguing that we can tense the entire truthmaking project and that, once we do, it is easy to satisfy truthmaker theory under presentism without forcing existing entities in the present to do truthmaking work for claims about the past (see, for instance, Kierland and Monton (2007) and Baia (2012)). To be clear: not all middle road presentists adopt a tensed approach to truthmaking. 6 My target, however, is the tensed version of the middle road, and so henceforth it is to that position that I will refer when speaking of middle road presentism.

My goal here is not to defend the middle road so conceived. It is, rather, to get clear on what, exactly, the ontological picture underlying middle road presentism might be, and to get clear on how this notion of tensed truthmaking is supposed to work. I begin by putting pressure on the proponent of the middle road to say more about the relationship between truth and ontology that underlies a tensed approach to truthmaking, identifying a key challenge that must be met (\$2). I go on to consider four ways of addressing the challenge, arguing that each is unsatisfactory ( $(3-4)$. Following this, I propose a hybrid solution to the challenge $(\S 5)$, one that combines elements from three of the four views considered in $\S 3-4$, before arguing that the solution is an intelligible, presentist position. I briefly defend the claim that the middle road view is distinct to the hard and easy road versions of presentism $(\S 6)$ and close by suggesting that something like the presentist position developed here will be necessary for developing an adequate version of the middle $\operatorname{road}(\S 7)$.

\section{The Challenge}

As noted, middle road presentists typically advocate a tensed approach to truthmaking. This involves taking standard truthmaker principles and reformulating those principles in a fundamentally tensed manner. So, for instance, consider what is, arguably, the weakest truthmaker principle (advocated by Lewis (2001) and Bigelow (1988)). I use here Lewis's (2001) formulation:

(SP) For any proposition $\langle p\rangle$ and any worlds $W$ and $V$, if $\langle p\rangle$ is true in $W$ but not in $V$, then either something exists in one of the worlds but not in the other, or else some $n$-tuple of things stands in some relation in one of the

\footnotetext{
${ }^{6}$ For instance, the Meinongian presentist discussed in $\S 4$ does not.
} 
worlds but not in the other. (Lewis 2001, p. 612).

To tense truthmaker theory, we replace (SP) with one of the following:

(QBSP) Truth supervenes on things, how things are, and the past about things and how things were. (Kierland and Monton 2007, p. 490)

(Presentist TSB) For any worlds $W_{1}$ and $W_{2}$, let $\psi$ be the proposition that something exists in one world but not the other, or else some object instantiates a property or a relation in one world but not the other. For any proposition $P$, if $P$ is true in $W_{1}$ but not in $W_{2}$, then $\psi$ or $\operatorname{WAS}(\psi)$ or $\operatorname{WILL}(\psi){ }^{7}$ (Baia 2012, p. 349)

The middle road presentist goes on to argue that presentism is well-placed to satisfy tensed truthmaker principles of the above kind. In order to satisfy these principles, there is no need to call the past into existence. Rather, these principles require only that the past existed. Because all presentist agree that the past existed, the core ontology of presentism is no bar to satisfying truthmaker theory. Which is to say that presentism is compatible with tensed truthmaker theory because the presentist can allow that claims about the past depend on the past, on 'how things were' (henceforth, this will be my phrase for that aspect of the past that truth is supposed to depend upon), even though the past does not exist. Baia, for instance, explicitly takes this line when he writes:

... that there were dinosaurs depends on past dinosaurs in the following sense: No worlds differ in whether that there were dinosaurs is true without also differing in whether dinosaurs existed. (Baia 2012, p. 349)

Tensing truthmaker theory is a central component of middle road presentism: it is key to the view. For by doing so, one can accept the core middle road claims: namely that propositions about the past are true, that truthmaker theory is unrestricted and that the truth of claims about the past does not depend on the present existence of any entities (it depends on entities that existed). But is tensing our truthmaker principles the end of the story? I am not convinced, for we can still ask: how, exactly, do truths about the past depend upon how things were, given that the past does not exist? Middle road presentists warn against asking such questions: truth depends on how things were, they say, and that is a primitive relationship, one that resists further investigation. I, for one, cannot help myself: what does it mean to say that truth depends on how things were?

\footnotetext{
' 'WAS' and 'WILL' are primitive, non-truth functional tense operators.
} 
We can say the words, but the words must paint an ontological picture and, for me at least, the picture offered thus far is painfully indistinct.

To animate the problem, consider again the hard road presentist. As noted, hard road presentists propose a restriction on truthmaker theory for claims about the past. But they typically go on to say things that sound very much like middle road presentism. Tallant (2009, p. 423), for instance, maintains that although propositions about the past do not depend upon ontology and thus lie beyond the scope of truthmaker theory, such claims are nevertheless true in virtue of how things were in the past; they are true in virtue of the past existence of truthmakers. Merricks (2007, p. xiii), another hard roader, makes a similar suggestion but, like Tallant, is clear that his proposal is to treat truths about the past as lying beyond the scope of truthmaker theory.

What we see then in the literature is something quite puzzling. Both the hard road presentist and the middle road presentist claim that propositions about the past are true because of how things were. However, the hard roader takes this to be equivalent to a restriction on truthmaker theory, while the middle roader takes this to be a broadening or reimagining of truthmaker theory. In order for the middle road position to be a genuinely distinct position, then, we need to know why the view is not simply the same old restriction on truthmaker theory being pushed on us by the hard roader. That requires an account of exactly how truthmaker theory gets satisfied and by what. If it is 'how things were' that is doing the work well and good but some account is required of what that means, otherwise it is unclear what the solution is supposed to be.

Here's another way to put the general point. What it is for a principle to be a truthmaker principle is for it to connect truth to ontology in a metaphysically robust manner. Merely stating a tensed principle and claiming that it is a truthmaker principle is therefore not enough. We need to know how truthmaking work is being done according to that principle. Put in difference-making terms: a difference in truth-value between worlds ought to correspond to a difference in the ontology of the two worlds. It is not obvious, however, what kinds of differences we might be tracking when talking about differences in how things were. Presumably, the tensed truthmaker theorist will tell us that we are tracking tensed differences between worlds. For instance, a world in which $<$ Caesar crossed the Rubicon $>$ is true differs from a world in which $<$ Caesar crossed the Rubicon $>$ is false in the following tensed respect: in the first world, Caesar crossed the Rubicon whereas, in the second world, Caesar did not cross the Rubicon.

On its own, however, that is not very illuminating. For it is just to state that there are tensed ontological differences between worlds that track differences in truth-value for claims about the past, differences that a tensed truthmaker principle adequately captures. The nature of these differences has not been explained, 
and so the broad ontological picture remains unclear. Moreover, our usual ontological pictures won't do. We cannot understand differences in how things were as differences in what exists or in the relations/properties that are instantiated, for that will collapse middle road into easy road presentism. We must, rather, understand differences in how things were as differences in what existed and the properties/relations that were instantiated between worlds, where that is something completely new.

So middle roaders must explain the relationship between truth and ontology proposed by a tensed approach to truthmaking. If this cannot be done, then I'm afraid we cannot view tensed principles such as (QBSP) or (Presentist TSB) as genuine truthmaker principles. At best, they look to be ways of capturing the same restriction on truthmaker theory underlying the hard road to presentism. Alternatively, if an account of the relationship between truth and ontology underlying these principles can be provided, but only at the cost of invoking presently existing entities of some kind, then the middle road will collapse into the easy road.

Of course, the challenge here is premised on the idea that we should take truthmaker theory metaphysically seriously, as a way of connecting truth up to ontology. Some middle road presentists may therefore wish to sidestep the challenge by 'deflating' truthmaking, giving up on the idea that we should take truthmaker theory seriously in this sense. In the following section, I provide some considerations against this deflationary move. This will motivate a more inflationary attitude to be discussed in $\S 4-5$.

\section{Deflationism}

Both hard and easy road presentists accept that truthmaker theory brings with it substantial ontological commitments. I suspect that for some, however, the tensed approach to truthmaker theory is supposed to require no such heavy-duty ontological posturing. When we say that $<$ Caesar crossed the Rubicon $>$ is true because Caesar crossed the Rubicon we are saying something painfully obvious that must be true and that does not require any further ontology to render it sensible. Baia (2012, p. 349) seems to take this line when he writes of (Presentist TSB):

It is key that, in defending [Presentist TSB], the presentist can hold that the truth of a proposition can depend on how the world was or will be ... without thereby being ontologically committed to merely past or future things.

Presentist TSB, then, is supposed to be ontologically light-weight. More generally, the middle road to presentism is supposed to be easy, as easy as Tarski's truth- 
schema. The connection to the T-schema is apt, especially in the context of a deflationary theory of truth. Deflationary theories of truth hold, roughly, that all there is to say about truth is captured by the Tarskian truth-schema:

$$
\mathbf{T}<p>\text { is true iff } \mathrm{p} \text {. }
$$

Truth so understood is also supposed to be metaphysically light-weight. The Tschema does not invite a metaphysics of truth of the robust kind offered by, say, correspondence theorists, who maintain that truth is a matter of correspondence to reality. As a corollary, truth understood via the truth schema is incapable of doing substantive metaphysical work in, say, facilitating the development of objections against a metaphysical theory.

A similar story might be told for tensed truthmaking. Perhaps all there is to say about tensed truthmaking is captured by the following tensed 'truthmaker schema':

Tense For any claim about the past, $\langle\psi\rangle,\langle\psi\rangle$ is true because $\psi$.

Where 'because' here is some kind of primitive sentential operator, one that expresses a syntactic relationship of priority between $\psi$ and $\langle\psi\rangle$. Once we have laid out the truthmaker schema, so the thought goes, we have said all there is to say about truthmaking in this domain. The tensed truthmaker schema does not invite a robust ontological interpretation of the sort demanded in the previous section. As a corollary, truthmaking so understood is incapable of doing any substantive metaphysical work in, say, facilitating the formulation of a truthmaker objection against presentism.

It is, perhaps, the Tense-schema and the associated deflationary attitude that proponents of (QBSP) and (Presentist TSB) are groping for. It would certainly explain the puzzlement that they tend to express when I ask them to explain the underlying ontology behind the tensed truthmaking approach, an approach taken to be so straightforward as to border on the inane.

The deflationary take on the tensed truthmaker approach can be formulated into a much more general thesis about truthmaking. All there is to truthmaking is the following generalised truthmaker schema:

TM For any claim $\langle\phi\rangle,\langle\phi\rangle$ is true because $\phi$.

Truthmaking is, on this view, as metaphysically uninteresting as truth and certainly cannot do any real work; there are no viable truthmaker arguments in metaphysics. 
If deflationism about truthmaking were a viable option, then matters would be easy indeed for the middle road presentist. All she would have to do is quote the Tense-schema or the TM-schema and off she goes. I seriously doubt, however, that deflationism is a useful way forward, for three reasons. First, it is very difficult to see what the subsantive difference between the T-schema and the TM/Tense-schemas really amounts to. If the TM/Tense-schemas just are Tarskian truth-schemas, however, then, as Asay and Baron (2014, p. 14) have argued, they are not truthmaker principles at all, just because the T-schema isn't. So appealing to these schemas does nothing to reconcile presentism with truthmaker theory. Second, even if the TM/Tense-schemas are distinct to the T-schema, the deflationary approach to truthmaking, at least as applied to the past, appears to imply that truths about the past make no substantive ontological demands. They do not, that is, require a story about the underlying metaphysics that coheres with the tensed truthmaker approach. But then the view sounds exactly like the hard road to presentism: the view according to which claims about the past do not depend upon anything. The middle road to presentism so understood would not be a genuine alternative to positions already on offer.

Perhaps that is unfair: truth does depend on being on the deflationary approach to truthmaking. It is just that the very notion of 'dependence on being' is far thinner, metaphysically speaking, than we realise. Indeed, exactly where the proponent of hard road presentism goes wrong is in taking the dependence of truth on being as a metaphysically substantive claim, one that must be rejected in order to save presentism. That is a mistake, says the proponent of the deflationary approach to truthmaking; stop taking metaphysics so seriously!

This brings us to the third problem with the deflationary approach: truthmaker theory is not obviously open to deflation. When we say that truth depends on ontology we mean something metaphysically robust by this claim. As Asay and Baron (2014, p. 14) argue, this is evidenced by the kinds of debates that go on in the truthmaking literature, and the seriousness with which those debates are treated. If truthmaker theory is deflated then all of the substantive issues in truthmaker theory seem either completely mysterious or else trivial to solve. It is, for instance, hard to see how we could have a substantive debate about the metaphysics of truthmakers - about what truthmakers really are - once the dependence of truth on ontology has been stripped of metaphysical import. Similarly, debates about the nature of the truthmaker relation - how exactly it is that we should understand the dependence at issue - appear just as pointless if truthmaking is metaphysically light-weight. Or consider the problem of negative existentials: one of the chief difficulties for maximalist truthmaker theories. This problem now seems utterly trivial to solve. Why is < there are no unicorns $>$ true? Well, because there are no unicorns of course! 
We can extend Asay and Baron's central insight a bit further: the deflation of truthmaking would not only make a mystery of truthmaker debates, it would also have substantial ramifications elsewhere. Truthmaking is supposed to give us a grip on issues to do with realism and anti-realism, constituting a framework for developing those debates (Asay 2012). It is also supposed to provide a way to catch metaphysical cheats: those who invoke dubious ontologies (Armstrong 2004; Sider 2001). To 'deflate' the dependence of truth on being is to set deflationism loose throughout these other areas of metaphysics. Suddenly realist and antirealist debates appear metaphysically light-weight, at least when framed in terms of truthmaking. Moreover, cheats caught via such deflationary means would be easily set free: why care about someone's cheating when that person's diagnosis as a cheat falls out of something that should not really be doing any substantial metaphysical work? Finally, because the operative notion of 'dependence' in the claim that truth depends on being crops up in a number of places in metaphysics, deflating it here is likely to force a deflationary attitude to whole swathes of the metaphysical enterprise.

To deflate truthmaking in the above way, then, is really to deny truthmaker theory and to step outside of the entire truthmaker project. It is also likely to require a very general deflationary attitude toward metaphysics. Now nothing I have said rules that out: one can certainly develop a metaphilosophical stance of this kind to get presentism out of trouble. But that would seem an incongruent thing to do, especially for a presentist. Presentism is built on the foundations of metaphysical seriousness. I worry then that deflationism about truthmaking is contrary to the very spirit of presentist metaphysics.

\section{Modified Ontology}

This brings us back to a more ontologically inflationary approach to the middle road. Such an approach faces the challenge outlined at the end of $\S 2$ : namely, to provide some account of what it means to say that truth depends on how things were. While I believe it is possible to make sense of this idea, doing so ultimately requires endorsing an ontological picture that, when first met, can seem quite bizarre. Moreover, the picture can seem unmotivated, since it might be thought that there are (by comparison) more sedate ontologies already available that would do just as well.

Instead of jumping straight to the positive proposal, then, I need to ease us into it. I will do this by canvassing three broad ontological pictures already available in the literature that one might be naturally inclined to use when developing an understanding of middle road presentism. I will argue in each case that the ontological picture being painted is unsatisfactory. To be clear: I will not be 
arguing that these accounts are implausible simpliciter, I lack the space for such a detailed critique. I will, rather, be arguing only that these accounts, at least as presented by their proponents, are not up to the task of supporting the middle road.

Note that this section is not merely an attempt to clear the way for the positive proposal in $\S 5$, though it is certainly that. Rather, by focusing on the reasons why these three ontological pictures are unsatisfactory, we can begin to triangulate a piece of negative space in which a satisfactory account of the ontology of middle road presentism must ultimately fit. This, in turn, will make the positive proposal easier to grasp, since it will be tailored to occupy the space so defined, and will be partially illuminated by its neatness of fit.

\subsection{The Brute Past}

The most natural place to start is with Kierland and Monton's (2007) brute past presentism, since it is perhaps the first version of middle road presentism to recognise the challenged outlined in $\S 2$. Kierland and Monton claim that the truth of propositions about the past depends on ontology in this sense: those propositions depend on past being, where past being is a sui generis ontological category. Of this category, they write:

The past is an aspect of reality, but it cannot be reduced to things or the properties they possess (i.e., how things are) ... what is the past? It is what has happened: what things existed and how they were. But what is that? To ask that question is to presuppose that the past must be explainable in other terms. And that presupposition may simply be false. (Kierland and Monton, p. 491)

Kierland and Monton call this category of past being 'the brute past'. Note that the brute past is not reducible to the sum total of past entities that, under nonpresentism, exist but which, under presentism, do not. Note also that the brute past has a particular shape; a kind of structure, one that describes a total world history. It is the shape of the brute past that is ultimately responsible for truths about the past. A world in which $<$ Caesar crossed the Rubicon $>$ is true and a world in which $<$ Caesar crossed the Rubico $>$ is false differ with respect to the shape of the brute past. It is by attending to historical evidence that we come to know what shape the past has (Kierland and Monton 2007, pp. 492-493).

So far so good. The Kierland and Monton line gets into trouble, however, when they say that while:

... the [brute] past is a fundamental aspect of reality ... we are willing to say 
that the [brute] past is a present aspect of reality. (Kierland and Monton 2007, pp. 496-597)

As Caplan and Sanson (2011, p. 202) argue, this admission forces Kierland and Monton into a dilemma. Either the brute past is what really happened, or it is not. If the brute past is what really happened, then it is implausible to hold that the brute past is a present aspect of reality. It would seem, rather, to be a past aspect of reality. For a present aspect of reality is how things are now, and cannot be plausibly understood as somehow constitutive of how things were. At best, a present aspect of reality might 'stand in' for the past, by representing past entities, or otherwise standing proxy for them. But it cannot itself constitute the past. If, however, the brute past is not what really happened - that is, does not constitute the past - but, rather, is just some extra aspect of present reality - some extra entity, say, or some extra property - that stands in for the past then the Kierland and Monton view fails to be a version of middle road presentism. For what the view really amounts to is this: there is a single, primitive aspect of the present that exists and that makes claims about the past true. Such a view has all of the hallmarks, and faces all of the troubles of the easy road to presentism.

The dilemma Caplan and Sanson raise is a serious one. But I do not think we should be too quick to throw out the Kierland and Monton line. For there is a key insight within the approach that must be recognised. The insight is this: to fully satisfy a tensed truthmaker principle we need to attribute some, positive ontological status to the past. For if the past is nothing at all ontologically speaking, then there will be no way to make sense of tensed truthmaking, which is supposed to connect truth to things that used to exist, and that used to possess properties. Kierland and Monton recognise this, and seek to 'beef up' the past by treating it as a sui generis ontological category. Where they go wrong is in treating the past as a present aspect of reality, since that calls it into existence. Still the difficulty Kierland and Monton face is instructive, for it partially reveals what is required to make the middle road succeed: the past must be included in the presentist's ontology. But how?

\subsection{Meinongianism}

Here's one option: Meinongianism. Meinongians draw a distinction between being and existence, a distinction I have thus far ignored. According to the Meinongian, non-existent entities are a part of being. Being therefore outruns existence. At the formal level, this is usually modelled by treating existence as a predicate, $E x$. Thus 'there exists something such that' is: $\exists \mathrm{x}(E x \wedge \ldots x \ldots)$ and 'all existing 
things are such that' is: ' $\forall \mathrm{x}(E x \rightarrow \ldots x \ldots)$ ' (Priest 2003, pp. 4-5). ${ }^{8}$ Meinongian presentism takes on the distinction between being and existence and holds that there are past things that do not exist. Past entities, properties, relations and so on are, on this view, some (albeit thin) addition to being. ${ }^{9}$

On this view, it is the non-existent things that are responsible for the truth of claims about the past. The ontological difference between a world in which $<$ Caesar crossed the Rubicon $>$ is true and $<$ Caesar crossed the Rubicon $>$ is false is that a world in which the proposition is true is one in which Caesar is crossing the Rubicon, in the past, even though he does not exist, whereas a world in which the proposition is false is one in which Caesar is not crossing the Rubicon in the past.

The Meinongian presentist gains all of the ontological resources available to the non-presentist when it comes to truthmaking, without the ontological cost in existing things. To be sure, there is an ontological cost to be paid of some order: an outlay on non-existent entities is required. But, arguably, that is a cost worth paying, since by doing so it is possible to attribute the past some positive ontological status, without thereby calling the past fully into existence. The result is an ontological picture of reality that is fit for truthmaking.

Set aside the various difficulties with positing non-existent entities, and with making sense of the distinction between things that exist and things that just are. The real trouble with Meinongian presentism is that it demotivates the tensed aspect of the tensed approach to truthmaking. For if we are allowed to accept that past entities are, even though they do not exist and to then use these non-existent entities for truthmaking purposes, then we can formulate an entirely tenseless truthmaker theory that takes, as input, things that 'are' in the Meinongian sense, and connects those up to truth using something like (SP) (Keller (2004, pp. 89-91) makes this point). ${ }^{10}$ This, however, would make a mystery out of the middle road presentist's insistence that tensing our truthmaker principles is key to the success of middle road presentism. ${ }^{11}$

So Meinongian presentism won't do, at least if we are to take the 'tensed'

\footnotetext{
${ }^{8}$ For a Meinongian semantics see Routley (1980).

${ }^{9}$ Something like Meinongian presentism is defended by Hinchliff (1996) as 'unrestricted presentism'.

${ }^{10}(\mathrm{SP})$ itself will not do: it requires supervenience on existing things. It can, however, be modified to require supervenience on things that have being.

${ }^{11}$ Note that Kierland and Monton (2007, p. 495) explicitly reject the Meinongian interpretation.
} 
aspect of middle road presentism seriously. ${ }^{12}$ Again, however, the Meinongian picture contains a key insight. As noted, the middle road must attribute some positive ontological status to the past. Calling the past into existence won't do. But then it would seem that the only option is to draw a Meinongian distinction between the existence of the past and past being. With such a distinction in hand, one can increase the ontological status of the past, without increasing it too much. As noted, standard Meingonian presentism demotivates the tensed truthmaker enterprise. So we need a new way of thinking about the distinction between existence and being that does not have this outcome. A useful way forward is to appeal to something like ontological pluralism, which is the third putative way of understanding the ontology of the middle road, and which I will now discuss.

\subsection{Tensed Ways}

Ontological pluralists appeal to the ancient notion that there are different kinds of existence. Turner (2010) develops the distinction between ways of existing in a rigorous way, via pluralism about basic quantifiers. For each notion of existence, existence $_{1} \ldots$ existence e $_{n}$, there is a distinct, semantically basic quantifier $\exists_{1} \ldots \exists_{n}$. The $\exists_{n}$ quantify over things that exist in each of the relevant ways. If a pink ball exists in the exists ${ }_{1}$ way, then: $\exists_{1} x(B x \& P x)$, if it exists in the exists 2 way, then: $\exists_{2} x(B x \& P x)$ and so on. Examples of things that might exist in different ways include: abstract versus concrete objects; fundamental versus non-fundamental objects and mind-dependent versus mind-independent objects.

Ontological pluralism is controversial but, for now at least, set aside the difficulties facing such a view. ${ }^{13}$ Rather, assuming that ontological pluralism is sensible, we can go on to differentiate between different ways of existing in time. By taking tense very seriously we can say that past, present and future entities all exist in different ways and, moreover, change their existential category with the passage of time. We can, that is, differentiate between existence in the pastish way $\exists_{A}$; the presentish way $\exists_{P}$ and the futurish way $\exists_{F} .{ }^{14}$ This gives us a unique take on the metaphysics of time and, more importantly for present purposes, furnishes us with a way to understand the ontological picture underlying tensed truthmaker principles.

To see this, consider again (Presentist TSB):

\footnotetext{
${ }^{12}$ Another option might be to adopt Baron's (2014) priority presentism. Priority presentism gives the past a positive ontological status, by imbuing it with a lower grade of existence. Priority presentism is insensitive to tense, however, in that it requires no tensed truthmaker principles, and so will demotivate the tensed aspect of the middle road in the same manner as Meinongian presentism.

${ }^{13}$ For defense, see McDaniel (2009) and Turner (2010)

${ }^{14}$ See McDaniel (ms.) for defense of this idea.
} 
(Presentist TSB*) For any worlds $W_{1}$ and $W_{2}$, let $\psi$ be the proposition that something exists in one world but not the other, or else some object instantiates a property or a relation in one world but not the other. For any proposition $P$, if $P$ is true in $W_{1}$ but not in $W_{2}$, then $\psi$ or $\operatorname{WAS}(\psi)$ or $\operatorname{WILL}(\psi)$.

To make sense of this principle as a genuine truthmaker principle, we interpret it using the three different kinds of existence represented by the semantically primitive quantifiers $\exists_{A}, \exists_{P}$ and $\exists_{F}$ to yield:

\section{(Presentist TSB*)}

For any worlds $W_{1}$ and $W_{2}$ :

1. Let $\alpha$ be the proposition that something exists $A$ in one world but not the other, or else some object instantiates ${ }_{A}$ a property or a relation in one world but not the other

2. Let $\beta$ be the proposition that something $\operatorname{exists}_{P}$ in one world but not the other, or else some object instantiates $P$ a property or a relation in one world but not the other

3. Let $\delta$ be the proposition that something exists $F$ in one world but not the other, or else some object instantiates ${ }_{F}$ a property or a relation in one world but not the other

4. For any proposition $P$, if $P$ is true in $W_{1}$ but not in $W_{2}$, then $\alpha$ or $\beta$ or $\delta$.

We can do the same for (QBSP) to yield:

(QBSP*) Truth supervenes on what exists $_{A}$, what exists $_{P}$ and what exists $_{F}$ and on which properties are instantiated ${ }_{A}, \operatorname{instantiated}_{P}$ and $\operatorname{instantiated}_{F}$.

Where, in both cases, the different ways of existing bleed off into different kinds of instantiation. For each way things can be, there is an associated way for properties and relations to be instantiated (denoted by subscripts for property instantiation in the principles above).

Truthmaker principles so understood are straightforward. The difference in ontology between worlds that corresponds to a difference in the truth-value of claims about the past is just a difference in what exists $A$ and/or differences in whatever properties/relations are $\operatorname{instantiated}_{A}$. In so far as we can make sense of different kinds of existence and, what's more, different ways of existing in time, 
then it looks like we have a coherent account of tensed truthmaking. Unfortunately, the picture of temporal ontology so painted, though intelligible, is not presentism; at least, not as we know it. Indeed, McDaniel (ms.) takes it to be a version of the 'moving spotlight' theory. To be sure, past entities do not exist in the same way present entities exist: they exist $_{A}$, as opposed to existing ${ }_{P}$. And, granted, these are fundamentally distinct kinds of existence. But the past still exists and that is contrary to the basic tenets of presentism.

Still, as with the previous strategies for understanding middle road presentism, the ontological pluralist approach preserves a key insight. If we are to take a tensed approach to truthmaking seriously, then it is not enough to simply tense our truthmaker principles. Rather, we must push tense right down into the basic ontology. For if we do not, then the resulting picture of truthmaking will be one in which some tenseless ontology is making true claims about the past. But then it is very difficult to see why any tensed truthmaker principle would be required: a standard tenseless one will do. This is exactly the problem facing the Meinongian view above. So what we need is something like the pluralist machinery for tenses, but that does not trade on tensed notions of existence per se.

\section{$5 \quad$ Tensed Being}

In the previous section, I considered three options for developing the middle road. This discussion revealed three core ontological aspects that such a view should have:

1. The past must be attributed some positive ontological status.

2. A distinction must be drawn between existence and being for the past.

3. Tense should be injected into the basic ontology.

By combining elements from each of the three views considered above, we can produce a version of presentism that possesses features (1)-(3) just mentioned. First, following Kierland and Monton, we begin by attributing some positive ontological status to the past. Second, just as the Meinongian presentist draws a distinction between existence and being, we draw a similar distinction, applying it to the past: the sense in which the past has a positive ontological status is just that it has being, but does not exist. Of course, we cannot follow the Meinongian in maintaining that there are past things, at least where the 'are' here is understood tenselessly. So this brings us to the third aspect: tense is taken ontologically seriously. However, rather than differentiating between different kinds of existence: past existence ( existence $_{A}$ ); present existence $\left(\right.$ existence $_{P}$ ) and future 
existence ( existence $_{F}$ ), we differentiate between different kinds of being, thereby tensing the basic ontology of Meinongianism. On this view, there is present being (things that are now); past being (things that were); and future being (things that will be). Each kind of being is distinct, constituting its own ontological category. Each kind of being is fundamental. Existence, on this view, is univocal: things either exist or they do not; being, by contrast, is tripartite, it comes in at least three flavours.

Call the combination of these three elements: Tensed Being Presentism (TBP). The view is, if you like, a kind of deep ontological pluralism: rather than endorsing pluralism about existence, it endorses pluralism about being (appropriately cleaved from existence), cutting it along tensed lines. TBP naturally avoids the difficulties facing each view considered in the previous section. It avoids the dilemma facing Kierland and Monton's view because while the past is treated as a distinct ontological category it is not treated as a present aspect of reality. To do so would be to annihilate the fundamental distinction between past and present being that TBP upholds. Similarly, TBP avoids the apparent redundancy of tensed truthmaker principles experienced by the Meinongian, because tense is treated as a fundamental aspect of ontology, something that our truthmaker principles ought to respect. Finally, TBP injects tense into basic ontology without calling the past into existence as the ontological pluralist does, and so does not obviously flout the core tenets of presentism.

In a moment I will argue that TBP is an intelligible, presentist position. For now, let us grant that the notion of past being is sensible. With this notion in hand, we can return to the challenge against middle road presentism voiced in $\S 2$. That challenge, it will be recalled, is to explain the relationship between truth and ontology that underlies tensed truthmaker theory in a way that preserves middle road presentism. To do this, we need (at a minimum) an account of the ontological differences that track truths about the past. According to TBP, the relevant differences are just those that have already been suggested: they are differences in how things were. But we now have a better sense of what that means: a difference in how things were is a difference in past being, where past being is a fundamental ontological category, one that is fundamentally distinct to present being. By satisfying tensed truthmaker theory in this way, TBP is wellpositioned to recover the core claims of middle road presentism. First, because tensed truthmaker principles are completely satisfied by past being, TBP does not force any restrictions on truthmaker theory. It can therefore satisfy claim (3) in the summary of middle road presentism provided in $\S 1$. Moreover, TBP satisfies truthmaker theory without holding that the truth of claims about the past depends on existing entities, so claim (2) is also satisfied. Finally, claims about the past are true, which gives us claim (1). 
Now, I admit that this is all very schematic. To put just a little flesh on the bones of TBP I need to do two things. First, I need to show that TBP can capture the core presentist thesis that only present entities exist. Second, I need to say more about what, exactly, the primitive category of past being is, and how we should understand it, lest I be charged with making a mystery out of tensed truthmaking. Note that, in order to carry out the first task, I will deploy a bit of technical machinery. My use of the technical machinery is primarily to provide a language in which to state the core presentist thesis that only present entities exist, so that the compatibility of this thesis with TBP can be drawn out.

Let us begin, then, by representing the distinction between past, present and future being with a new kind of quantifier. Ontological pluralists introduce different kinds of existential quantifiers to do similar work at the level of existence. The standard Meinongian strategy would be to take these quantifiers and then differentiate between being and existence via the existence predicate. Proceeding that way would make the position I am outlining quite similar to ontological pluralism, formally speaking. Since I believe that the difference between the views is greater than the similarity in formalism would suggest, I will, instead, introduce a 'being' quantifier, a 'beifier': $\exists \mathrm{B}$. The difference between $\exists \mathrm{B}$ and $\exists$ lies primarily with the domain. $\exists \mathrm{B}$ ranges over a domain of entities that possess being, not all of which need to exist. $\exists$, by contrast, ranges over existing entities.

Just as for each tensed way of existing some ontological pluralists posit a semantically primitive tensed existence quantifier $-\exists_{A}, \exists_{P}, \exists_{F}$ - for each tensed way of being there is a tensed beifier - $\exists_{A}$ for past being, $\exists_{P}$ for present being and $\exists_{F}$ for future being. Each beifier ranges over a distinct domain of entities, corresponding to a different kind of being. Universal beifiers can be introduced in the ordinary way for quantifiers via the singular beifier plus negation, e.g.:

$$
\begin{aligned}
& \text { 1. } \neg \forall \mathrm{B}_{A} \mathrm{x} \dashv \vdash \exists \mathrm{B}_{A} \mathrm{x} \neg \\
& \text { 2. } \forall \mathrm{B}_{A} \mathrm{x} \dashv \vdash \neg \exists \mathrm{B}_{A} \mathrm{x} \neg
\end{aligned}
$$

Note that implication does not necessarily carry across tensed beifiers. It is not always the case, for instance, that $\exists \mathrm{B}_{A} \mathrm{x} \Psi \mathrm{x} \rightarrow \mathrm{B}_{P} \mathrm{x} \Psi \mathrm{x}$ for any $\Psi$ (where $\Psi$ is a predicate variable), though this may hold in some cases. Other than that, beifiers behave as normal quantifiers within their given domain. By associating names with domains of being via a subscript we can carry out beifier generalisation: e.g. $\mathrm{Pa}_{A} \vdash \exists \mathrm{B}_{A} \mathrm{xPx}$, as well as universal instantiation for any universal beifier: e.g. $\forall \mathrm{B}_{A} \mathrm{xPx} \vdash \mathrm{Pa}_{A}$ and so on. What we cannot do is generalise or instantiate out of beifiers across domains. So, for instance: $\mathrm{Pa}_{A} \nvdash \mathbb{B}_{P} \mathrm{xPx}$. That's because the domains are distinct. 
The condition that all and only present entities exist can be stated using the present beifier and the property of existence, represented by the existence predicate ' $E x$ ', as follows:

3. $\exists \mathrm{x}(\ldots x \ldots) \leftrightarrow \exists \mathrm{B}_{P} \mathrm{x}(\mathrm{Ex} \wedge \ldots \mathrm{x} \ldots)$

4. $\forall \mathrm{B}_{P} \mathrm{xEx}$

Sequent 3 tells us that only present entities exist, sequent 4 tells us that all present entities exist. Together, sequents 3 and 4 represent the core thesis of presentism. TBP has the capacity to uphold both sequents. Because TBP draws a distinction between being and existence, it is free to spread existence where it likes. Accordingly, it throws existence over everything that has present being, thereby upholding 4. Similarly, because TBP draws a distinction between different kinds of being, and because it allows that existence and being come apart, it is not forced to place existence onto past or future being. Instead, it happily restricts existence to present being only. So TBP upholds 3. Because TBP upholds both claims, it is a genuinely presentist view.

One might disagree: with regard to the tensed existential quantifiers $\exists_{A}, \exists_{P}$ and $\exists_{F}$ it is always possible to introduce a global quantifier, $\exists$ and stipulate that $\exists \mathrm{x}(\ldots \mathrm{x} \ldots) \dashv \exists_{A} \mathrm{x}(\ldots \mathrm{x} \ldots) \vee \exists_{P} \mathrm{x}(\ldots \mathrm{x} \ldots) \vee \exists_{F} \mathrm{x}(\ldots \mathrm{x} \ldots)$. One can then claim that tensed existential quantifiers are nothing more than restrictions of $\exists$. So too can one introduce a global beifier $\exists \mathrm{B}$ and stipulate that $\exists \mathrm{Bx}(\ldots \mathrm{x} \ldots)$ $\dashv \exists \mathrm{B}_{A} \mathrm{x}(\ldots \times \ldots) \vee \exists \mathrm{B}_{P} \mathrm{x}(\ldots \times \ldots) \vee \exists_{F} \mathrm{x}(\ldots \times \ldots)$. In the case of tensed quantifiers - and, indeed, in the case of ontological pluralism more generally - the presence of the global quantifier might be thought to pose a problem. For if there is such a global quantifier and if the tensed quantifiers are just restrictions of the global quantifier, then this may seem to have ontological import: there really is only one kind of existence and that is represented by $\exists$. The tensed quantifiers are not genuinely distinct kinds of existence, they are simply ways of carving up the domain of existing things. So too you might think that because we can stipulate the global beifier $\exists \mathrm{B}$, there is really only one kind of being. The other tensed beifiers are just different ways of cutting up this total domain. If that were so, one might argue, then it would be very difficult to restrict existence to only present entities, since it is the robust distinction between kinds of being that facilitates such a restriction. TBP would not be a presentist view after all.

This worry and others like it have already been dealt with by proponents of ontological pluralism, and so I will be brief (see Turner 2010, pp. 13-21). The key to the issue is conceptual priority. Beifiers, as I am using them here, merely represent and so render perspicuous an underlying ontological picture, one 
according to which there are three distinct categories of being. Beifiers do not determine the underlying picture of reality; the picture of reality is conceptually prior to the language we use to describe it. Indeed, it is the picture that motivates the division between beifiers, and it is the picture that the language is ultimately aiming to track. So while we can certainly introduce new quantifiers into our language that enable us to talk about all three kinds of being at once, disjunctively, we should resist the idea that this tells us anything about reality, or else be charged with reading metaphysics off the structure of a language. This is just to say that merely being able to introduce a global beifier does not reveal anything deep. Of course, one could take a different view, treating ontology as the business of getting the quantifiers straight. But I take a 'metaphysics first' approach, and for good reason. As Dyke (2008) has argued, taking a 'language first' approach opens one up to serious methodological problems.

You might wonder, then, why I have spent any time at all on the beifiers. Well, note that a metaphysics first approach does not imply that formal languages have no place, it merely suggests that we should not attempt to 'read off' ontology from the structure of such languages. The metaphysics first approach allows that we can learn a lot by modelling the structure of reality formally. We can render structural connections precise that may be only dimly imagined prior to such formalisation. Ultimately, though, the formal work is being pressed into the service of an underlying view of ontology and not vice versa. At any rate, that is the spirit in which I have used the language above: TBP is a presentist view because it upholds an ontology that is accurately represented by a formally stated version of the core presentist thesis. The language helps us to reveal TBP's presentist credentials, but does not determine that TBP has those credentials.

The formal machinary is important for another reason. It is indispensable for adequately expressing the view I am developing. When talking about the domains of past or future being, it is hard not to slide into use of tenseless language, saying things like 'the domain of past being is the domain of things that were $x$ '. This 'is' makes it sound as though the tenseless Meinongian 'are' considered in $\S 4$ underlies the ontological picture being painted. But it is, strictly speaking, a mistake to say that the domain of past being 'is' anything in the tenseless sense, but it is also necessary to say such things when using English. The formal machinary will, ultimately, replace this way of talking, providing a fundamentally tensed way to talk about things in the domain of past being.

For instance, a very natural thing to say is that the domain of past being 'is' constituted by things that used to exist, or that the domain of future being 'is' constituted by things that will exist. I understand the relationship between tensed beifiers and tensed existence statements as follows. If $\exists_{A} \mathrm{xPx}$, then it follows that there existed something that used to possess property $P$. Similarly if $\exists_{F} \mathrm{xPx}$ then 
it follows that there will exist something possessing $P$. We can sharpen this up through the use of tense operators. Using WAS and WILL to represent sentential tense operators for 'it was the case that' and 'will be the case that' respectively, we can translate statements of the form ' $x$ existed' as $\mathbf{W A S}(\exists \mathrm{x} \ldots)$ and statements of the form ' $x$ will exist' as $\mathbf{W I L L}(\exists \mathrm{x} \ldots$.$) . The relationship between beifiers and$ tensed existence statements then is:

$$
\begin{aligned}
& \text { 5. } \exists \mathrm{B}_{A} \mathrm{x}(\ldots \mathrm{x} \ldots) \leftrightarrow \operatorname{WAS}(\exists \mathrm{x}(\ldots \mathrm{x} \ldots)) \\
& \text { 6. } \exists \mathrm{B}_{F} \mathrm{x}(\ldots \mathrm{x} \ldots) \leftrightarrow \operatorname{WILL}(\exists \mathrm{x}(\ldots \mathrm{x} \ldots))
\end{aligned}
$$

which, together, express a relationship between past/future being and present being that can be unpacked via the relationship between $\exists \mathrm{B}_{P}$ and $\exists$ to yield:

$$
\text { 7. } \exists \mathrm{B}_{A} \mathrm{x}(\ldots \mathrm{x} \ldots) \leftrightarrow \mathbf{W A S}\left(\exists_{P} \mathrm{x}(\operatorname{Ex} \wedge \ldots \mathrm{x} \ldots)\right)
$$

$$
\text { 8. } \exists \mathrm{B}_{F} \mathrm{x}(\ldots \mathrm{x} \ldots) \leftrightarrow \mathbf{W I L L}\left(\exists_{P} \mathrm{x}(\mathrm{Ex} \wedge \ldots \mathrm{x} \ldots)\right)
$$

More generally, then 'the domain of past being is the domain of things that were $x$ 'becomes: $\forall \mathrm{B}_{A} \mathrm{x}(\mathbf{W A S}(\Psi \mathrm{x}))$.

Obviously, being able to say things about past being in the language of beifiers does not let me off the hook with respect to the provision of a metaphysics for TBP. It is therefore incumbent on me to say a bit more about the ontological picture I am trying to paint. This returns us to the second aspect of TBP previously slated for development: what does it mean to say that past, present and future being are distinct ontological categories? More carefully: given that entities in the domain of past being do not exist and given that there 'are' no past entities in the Meinongian sense of 'are' (the 'are' used by Meinongian presentism), what is the domain of past being supposed to be? ${ }^{15}$

Here's my first pass answer to this question: the domain of past being is the domain of things that were. Suppose you press me: what does it mean to say that the domain of past being is the the domain of things that were? Rather than provide an independent analysis of this notion and thus of what it is to fall within the domain of past being, I prefer, in the first instance, to turn the question back. What does it mean to say that there 'are' things in the ordinary, non-Meinongian sense of being, used by non-presentists, the one that is typically connected to 'existence'? Either there is an answer to this question, or there is not. If there is no answer to this question, then we should not expect an answer to the question

\footnotetext{
${ }^{15}$ A similar question can be asked of future being. Everything I say below can be applied to future being as well. See fn. 13 .
} 
of what it means to say that something was. If there is an answer to this question, then whatever that answer is I can tense it and deploy it as an analysis of what it is to fall within the domain of past being.

For example, suppose one claims that what it means for something to be is for that thing to possess causal powers. Then I will say: what it means for something to have been is for that thing to have possessed causal powers. The domain of past being corresponds to things that used to be powerful $\left(\forall \mathrm{B}_{A} \mathrm{x}(\mathbf{W A S}(\mathrm{Px}))\right.$. Alternatively, suppose one claims that to be is to be concrete. Then I will say: to have been is to have been concrete. The domain of past being is populated by the formerly concrete things $\left(\forall B_{A} x(\mathbf{W A S}(\mathrm{Cx}))\right.$. If one continues to press the question with regard to the analysis of past being then, at each step, I will turn the question back. Unless analyses can be produced ad infinitum there will be a point in this to and fro at which one must accept that there is no further analysis available of what it is to be: being is at some level a primitive notion. However, if being is at some level a primitive notion, then the same can be said for past being: past being is at some level a primitive notion and, as such, admits of no further analysis.

Whatever our views about being in the non-Meinongian sense, then, we have an account of past being available, one that is every bit as good as our account of what it is to be. Suppose, however, one offers an analysis of being as follows. What it means for something to be is for that thing to be located in spacetime. If that is the correct analysis, then you might think there is no tensed version. It makes no sense to speak of something that used to be in spacetime. For that is to inject an unwanted tensed aspect into the notion of spacetime, perhaps even suggesting that spacetime itself is located in a higher temporal dimension.

Fortunately, however, this analysis of being will not do. If what we mean by being is tied up with location within spacetime, we thereby rule out any metaphysical view that takes entities outside of spacetime seriously, like Platonism (which countenances the existence of abstract entities) or dualism (which countenances the existence of non-physical entities). Now, it may well be that these views are implausible on independent grounds, but they are not to be ruled out given what we mean by 'being'. Similar considerations sink other apparently 'untensable' proposals. Indeed, there is, I believe, a general moral here: an analysis of being that is untensable also tends to be overly restrictive. So much the worse for untensable accounts of being.

I therefore offer the following as a positive characterisation of past being. At the most general level, the domain of past being is a domain of non-existent entities that used to possess the property of existence. We can gain a further grasp on this domain by comparing it to the domain of fictional entities. Fictional entities are, like past entities, non-existent entities. However, fictional entities never used 
to exist. We can use the double contrast with existence and fictional entities to give a statement of past being as follows: ${ }^{16}$
$A$ is the domain of past being $=d f$
(i) $\forall \mathrm{B}_{A} \mathrm{x}(\mathbf{W A S}(\mathrm{Ex} \ldots \wedge \ldots))$, (ii) $\forall \mathrm{B}_{A} \mathrm{x} \neg \mathrm{Ex}$ and (iii) $\forall \mathrm{B}_{A} \mathrm{x}(\neg \mathbf{F I C T}(\mathrm{Ex}))$.

Where FICT is a story operator, which reads: according to the fiction..., and where the elipses in (i) represent further conditions to be added as needed (e.g. concreteness).

In sum, past being is (1) the result of conceptually combining Meinongianism and ontological pluralism; (2) definable by taking the definition of present being and tensing it and (3) further characterisable via the twin contrast with existence and fictional non-existence. That gives us a pretty good grasp on the notion, one that is at least as good as our grasp on present being. So past being is intelligible. Because I have already shown that TBP upholds presentism, it follows that TBP is an intelligible presentist position.

\section{Back to the Easy Road?}

I have claimed that TBP is a genuine middle road view, one that is distinct to the hard and easy roads. But is that right? Here's one reason to worry. In a recent paper, Baron (forthcoming) argues that (what I have called) the hard road to presentism collapses into easy road presentism. The basic argument is this. Consider the proposition: < Suzy knows that dinosaurs existed $>$. Suppose it is true. Intuitively, this is a claim about the present. Accordingly, hard road presentists are forced to admit that it possesses a truthmaker; an entity that necessitates its truth. Knowledge, however, is factive. So the truth of $<$ Suzy knows that dinosaurs existed $>$ necessitates the truth of $<$ dinosaurs existed $>$. By the transitivity of necessitation, then, the truthmaker for $<$ Suzy knows that dinosaurs existed $>$ also necessitates the truth of $<$ dinosaurs existed $>$. Consequently, the hard road presentist is committed to the existence of some entity, $E$, that necessitates the truth of a claim about the past, $P$. The trouble is that the only options for understanding what $E$ might be are precisely the options that the easy road presentist has available to her for providing truthmakers for claims about the past. It follows, then, that a hard road presentist must call upon the same kinds of entities - tensed properties, abstract objects, memories in God's mind and so on - as the easy road

\footnotetext{
${ }^{16}$ For future being: $F$ is the domain of future being $=d f(\mathrm{i}) \forall \mathrm{B}_{F} \mathrm{x}(\mathbf{W I L L}(\mathrm{Ex} \ldots \wedge \ldots)$ ) (ii) $\forall \mathrm{B}_{F} \mathrm{x} \neg \mathrm{Ex}$ and (iii) $\forall \mathrm{Bx}(\neg \mathbf{F I C T}(\mathrm{Ex}))$.
} 
presentist, and so the hard road boasts no advantages over the easy road. ${ }^{17}$

Now, note that the middle road presentist also accepts that $<$ Suzy knows that dinosaurs existed $>$ can be true. So it would seem that she, too, is committed to some entity $E$ that necessitates the truth of such a proposition. If the only options available to the middle road presentist for understanding $E$ are the same as those available to the easy road presentist, then middle road presentism will, like hard road presentism, collapse into easy road presentism. An unwelcome result indeed. Fortunately, however, the middle road presentist has another option available to her, an option that is not available to an easy road presentist, and TBP helps us to see that. The easy and hard road presentists are forced to say that $E$ is some presently existing entity. As Baron notes, $E$ will (probably) be a complex consisting of an appropriately formed mental state $M$ possessed by Suzy, along with $T$ : a tensed property, abstract object, memory in God's mind and so on. The middle road presentist, by contrast, can maintain that $E$ is not a purely present entity, it is a complex consisting of an appropriately formed mental state $M$ plus an aspect of past being, $B$, namely whatever it is that, according to TBP, grounds the truth of $<$ dinosaurs existed $>$. In this way the middle road presentist holds a similar view to the non-presentist. A non-presentist will also maintain that what necessitates the truth of $<$ Suzy knows that dinosaurs existed $>$ is an appropriately formed mental state $M$ plus whatever it is that grounds the truth of dinosaurs existed. The difference is that what grounds the truth of $<$ dinosaurs existed $>$ for a non-presentist is an existing entity, whereas for the middle road presentist it is something that does not exist, but that 'has' past being.

The middle road presentist, then, can escape Baron's argument. This brief discussion has been instructive. For what it shows is that if Baron's argument is sound, then the only two live options available for addressing the truthmaker objection against presentism are the easy and middle roads. That makes the development of the middle road position outlined here all the more important. ${ }^{18}$

\section{Conclusion}

I recognise that there is a lot more to do. TBP demands a thorough explication and defense and I cannot hope to carry out that project in this paper. Instead, I will close by noting that something like TBP will be required to render middle road presentism successful, and so the burden does not lie with me alone. For consider that features (1)-(3) mentioned at the beginning of $\S 5$, the very features

\footnotetext{
${ }^{17}$ Baron's argument is a version of an argument presented by Jago (2012) against nonmaximalist solutions to the problem of negative existentials.

${ }^{18}$ Things may be worse still: Baron (2013) has also argued that the easy road fails. So the middle road option may be the only viable way forward for the presentist.
} 
that TBP is tailor-made to capture, are each individually necessary for accommodating genuinely tensed truthmaking. First, if the past is attributed no positive ontological status, then tensed truthmaker principles cannot be counted as ways of developing truthmaker theory, since the world will not be holding up its end of the relationship between truth and ontology that those principles propose. Second, if no distinction is drawn between existence and being, then there will be no way to attribute some positive ontological status to the past, without calling it into existence. And third if tense is not injected into the basic ontology, then the tensed aspect of truthmaker theory will be otiose.

Now, it may be that there is some other view - a view that is not TBP - that can capture these three features. I cannot rule that out. However, it is likely to deploy a very similar core ontology to TBP, and so is likely to be controversial in exactly the same ways. For any such view will require a fundamental distinction between existence and some $x$, where $x$ is a kind of positive ontological status. Such a view will also require that $x$ be fundamentally tensed, in order to justify the use of tensed truthmaker principles to handle truths about it. The necessity of TBP, or something like it, for developing a middle road presentism that takes tensed truthmaking seriously is important. For as noted in $\S 1$, my central goal in this paper is to reveal the underlying ontological picture needed to make sense of middle road presentism so conceived. That goal has been met: TBP is the answer. It is now up to the middle road presentist to give the view a solid defense.

\section{References}

Armstrong, D. (2004) Truth and Truthmakers. (Cambridge: Cambridge University Press).

Asay, J. (2012) A Truthmaking Account of Realism and Anti-Realism. Pacific Philosophical Quarterly 93(3), 373-394.

Asay, J. and Baron, S. (2014) The Hard Road to Presentism. Pacific Philosophical Quarterly. Online First. DOI: 10.1111/papq.12029.

Baron, S. (2013) Presentism, Truth and Supervenience. Ratio 26(1), 3-18.

Baron, S. (2014) The Priority of the Now. Pacific Philosophical Quarterly. Online First. DOI: 10.1111/papq.12030.

Baron, S. (forthcoming) There is No Easy Road to Presentism. American Philosophical Quarterly.

Baia, A. (2012) Presentism and the Grounding of Truth. Philosophical Studies $159(3), 341-356$.

Bigelow, J. (1988) The Reality of Numbers: A Physicalist's Philosophy of Mathematics. (Oxford: Oxford University Press). 
Bigelow, J. (1996) Presentism and Properties. Philosophical Perspectives, 10, $35-52$.

Bourne, C. (2006) A Future for Presentism. (Oxford: Oxford University Pres).

Cameron, R. (2011) Truthmaking for Presentists. In Oxford Studies in Metaphysics Vol. 6, Karen Bennett and Dean W. Zimmerman (Eds.), 55-101. (Oxford: Oxford University Press).

Cameron, R. (2008) How to be a Truthmaker Maximalist. Nô̂s, 42(3), 410-421.

Caplan, B, \& Sanson, D. (2011) Presentism and Truthmaking. Philosophy Compass 6(3), 196-208.

Crisp, T. M. (2007) Presentism and the Grounding Objection. Nô̂s 41(1), 90-109.

Dyke, H. (2008) Metaphysics and the Representational Fallacy. (New York: Routledge).

Goff, P. (2010) Orthodox Truthmaker Theory Cannot Be Defended by Cost/Benefit Analysis. Analysis 79(1), 45-50.

Heathwood, C. (2007) On What Will Be: Reply to Westphal. Erkenntnis 67(1), $137-42$.

Hinchliff, M. (1996) The Puzzle of Change. Philosophical Perspectives 10, 119-36.

Jago, Mark. 2012. The Truthmaker Non-Maximalist's Dilemma. Mind, 121(484), 903-918.

Keller, S. (2004) Presentism and Truthmaking. In Oxford Studies in Metaphysics Vol. 1, Dean Zimmerman (Ed.), 83-107. (Oxford: Oxford University Press).

Kierland, B., \& Monton, B. (2007) Presentism and the Objection from BeingSupervenience. Australasian Journal of Philosophy 85(3), 485-497.

Krämer, S. (2010) How Not to Defend Ontological Cheats. Analysis 70(2), 290-296.

Lewis, D. (2001) Truthmaking and Difference-Making, Noûs, 35(4), 602-615.

Markosian, N. (2004) A Defense of Presentism. In Oxford Studies in Metaphysics Vol. 1, Dean Zimmerman (Ed.), 47-82. (Oxford: Oxford University Press).

McDaniel, K. (2009) Ways of Being. In Metametaphysics, David Chalmers, David Manley and Ryan Wasserman (Eds.), 290-319. (Oxford: Oxford University Press).

McDaniel, K. (ms) Ways of Being and Time.

McKinnon, N., \& Bigelow, J. (2012) Presentism, and Speaking of the Dead. Philosophical Studies 160(2), 253-263.

Merricks, T. (2007) Truth and Ontology. (New York: Oxford University Press).

Priest, G. (2003) Meinongianism and the Philosophy of Mathematics. Philosophia Mathematica 11(3), 3-15.

Rhoda, A. R. (2009) Presentism, Truthmakers, and God. Pacific Philosophical Quarterly 90(1), 41-62.

Routley, R. (1980) Exploring Meinong's Jungle and Beyond: An Investigation of 
Noneism and the Theory of Items. (Canberra: Australian National University).

Sanson, D., \& Caplan, B. (2010) The Way Things Were. Philosophy and Phenomenological Research, 81(1), 24-39.

Sider, T. (1999) Presentism and Ontological Commitment. The Journal of Philosophy 96(7), 325-347.

Sider, T. (2001) Four-Dimensionalism: An Ontology of Persistence and Time. (Oxford: Oxford University Press).

Sider, T. (2003) Reductive Theories of Modality. In The Oxford Handbook of Metaphysics, Michael J. Loux and Dean Zimmerman (Eds.), 180-208. (Oxford: Oxford University Press).

Smith, B. (1999) Truthmaker Realism. Australasian Journal of Philosophy 77(3), 274-291.

Tallant, J. (2009) Ontological Cheats Might Just Prosper. Analysis 69(3), 422-430.

Turner, J. (2010) Ontological Pluralism. The Journal of Philosophy, 107(1), 5-34. 